\title{
Erratum to: Randomized open label phase III trial of CEOP/IMVP-Dexa alternating chemotherapy and filgrastim versus CEOP/IMVP-Dexa alternating chemotherapy for aggressive non-Hodgkin's lymphoma (NHL). A multicenter trial by the Austrian Working Group For Medical Tumor Therapy
}

\author{
M. A. Fridrik • R. Greil • H. Hausmaninger • O. Krieger • P. Oppitz • \\ M. Stöger • J. Klocker • M. Neubauer • W. Helm • J. Pont • B. Fazeny • \\ M. Hudec • I. Simonitsch • T. Radaszkiewicz
}

Published online: 18 December 2013

(C) Springer-Verlag Berlin Heidelberg 2013

Erratum to: Ann Hematol (1997) 75:135-140

DOI 10.1007/s002770050330

The original version of this article inadvertently contained a mistake. In Fig. 4, overall survival the labels were mixed up.

The online version of the original article can be found at http://dx.doi.org/ $10.1007 / \mathrm{s} 002770050330$

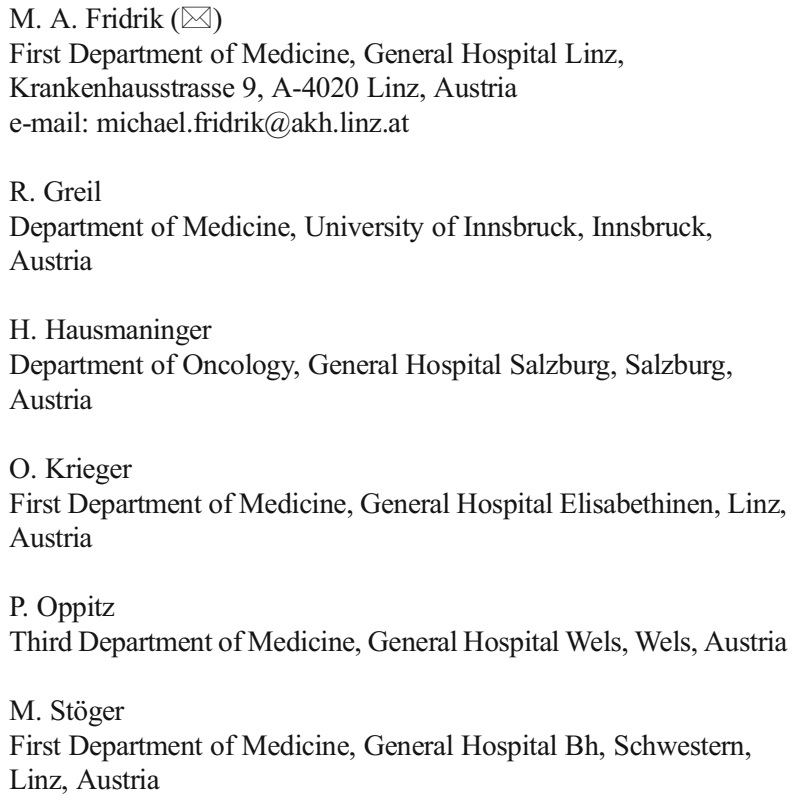

The label for the solid line must be changed to CEOP/IMVPDexa+filgrastim, and for the dotted line to CEOP/IMVP-Dexa.

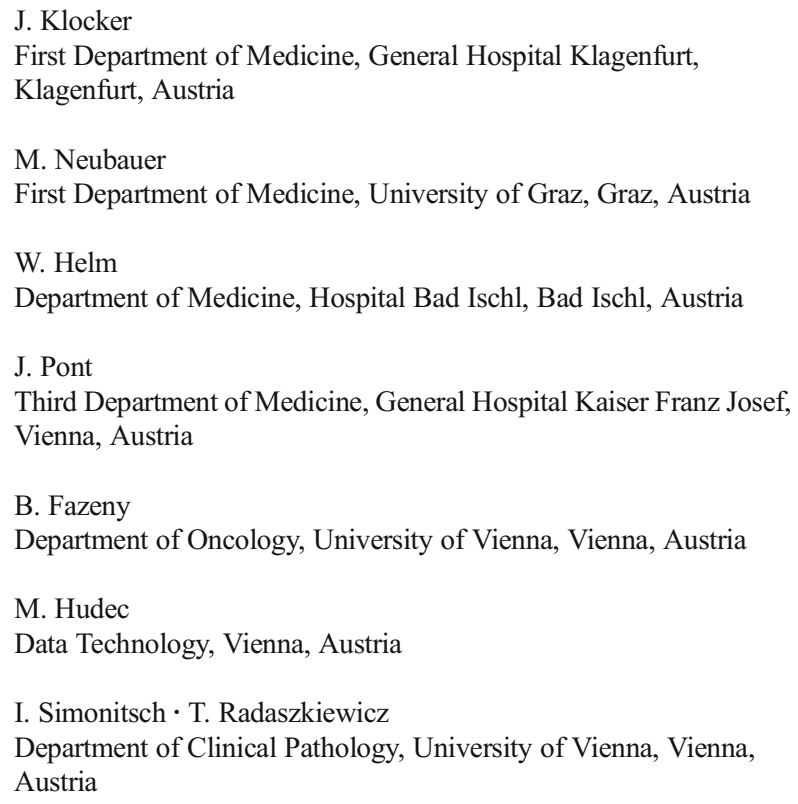




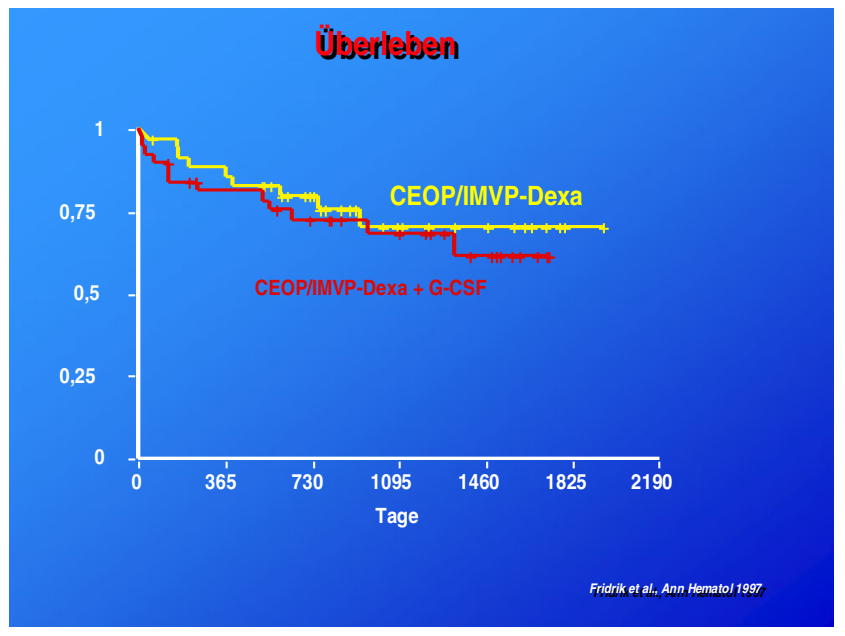

